\title{
MESIANISMO PERUANO. DOS DISCURSOS
}

\author{
Marcos YAURI MONTERO \\ Universidad Ricardo Palma \\ marcos.yaurim@urp.pe
}

\begin{abstract}
RESUMEN
Los países latinoamericanos con un largo pasado colonial y una vida autónoma que no termina de bordear los dos siglos, no han superado la inestabilidad política y social. El Perú no es una excepción. Aquí, los golpes de estado y las dictaduras, la crisis institucional y el caos en la gestión pública sumados a la devaluación de la clase política han desencadenado desencanto y desconfianza. La conciencia colectiva oscila entre el pasado lejano que cree fue feliz o aguarda al héroe salvador. Todo esto configura una posición milenarista y mesiánica que este artículo intenta explicar con la intención de que la ciudadanía ejerza su capacidad de discernimiento.
\end{abstract}

\section{PALABRAS CLAVE}

Milenarismo, mesianismo, Inkarrí, Taki Onqoy

\section{PERUVIAN MESIANISM. TWO SPEECHES}

\begin{abstract}
The Latin American countries with a large colonial past and autonomous life that still have not reached the two centuries, have not overcome political and social stability either. Perú is not an exception. Dictatures and devaluation of political class have caused distrust. The collective consciousness hopes the returning of Inca past. The whole statement is a Millenariam position that this article tries to explain with the purpose of citizens practice their autonomous individuals with capacity of discernment.
\end{abstract}

\section{KEYWORDS}

Millenariam, Inkarrí, Taki, Onqoy

Recibido: 4 /4/2017

Aprobado: 15/10/2017 


\section{Introducción}

La idea del fin del mundo ha estado presente en la filosofía y la religión de muchos pueblos como respuesta a tiempos de grave crisis en los que la desaparición de la existencia del universo y de la vida podría ocurrir. A nivel mundial, esta idea conocida como milenarismo, en Occidente tiene su origen en la tradición europea y cristiana. Los mitos que al principio le fueron dando forma involucraban las ideas del eterno retorno, los cambios cíclicos en la historia de la humanidad, la creencia que en los albores del mundo existió una edad de oro primitiva (el paraíso perdido). A estas ideas fue añadida la fe en un apocalipsis que traería de regreso al Mesías y con su llegada se daría inicio a un tiempo nuevo con un nuevo cielo y una nueva tierra tras la derrota de las fuerzas del mal.

El milenarismo cristiano es una de esas formas de pensamiento plasmada en el Apocalipsis de San Juan; $y$, de acuerdo a las ideas allí escritas Cristo gobernará el mundo por un período de mil años. Otros pensadores, como Isidoro de Sevilla en su libro Etimologías (626) pregonó que la duración de la edad del mundo sería de seis mil años a partir de Adán. El siglo X, en la baja Edad Media, fue una época histórica de grandes miedos causados por epidemias como el "mal de los ardientes", guerras desatadas por rivalidades feudales, las invasiones normandas, los grandes fenómenos cósmicos: eclipses de luna, hambres generalizadas, presencia de cometas en el cielo o lluvia de estrellas, la permanencia de un meteoro en el cielo del año mil durante tres meses. Después del año mil el demonio estaría acechando a los hombres desde los bosques o manantiales. Y todo este desastre tendría una causa; los pecados de los hombres. El fin llegaba a la tierra; el año 1033 era el milenio de la Pasión de Cristo.

Estos conceptos escatológicos de la catástrofe apocalíptica sufrieron el embate de una nueva visión. El monje cisterciense, Joaquín de Fiore (1149-1202) sustituyó la idea de la catástrofe del fin por la idea optimista de la llegada de una nueva era próxima. Se basó en la fe de la Trinidad, y según esta, la historia es una sucesión en ascenso de tres edades: la del Padre que se extiende desde la creación hasta Cristo; la edad del Hijo que comenzó con la encarnación de Cristo y que continúa con la Iglesia cuyo fin se acerca; y, la edad del Espíritu que está por llegar y con esta se realizará la historia de la salvación. Esta idea de Joaquín de Fiore, es llamada el mito o la lógica del Gran Tiempo. Es una visión lineal y no significa un simple cambio sino una revolución que no impacta solamente a la religión sino afecta a toda la vida, a la estructura y cultura de los pueblos. Es una revolución porque cada edad no es solo un cambio sino significa una superación permanente, un progreso; todo cambio es un movimiento en ascenso. Apoyándose en San Pablo, Joaquín de Fiore proclamó que la edad del Espíritu será del Evangelio Eterno, tiempo de paz, justicia, de la contemplación. Este nuevo tiempo será de embriagadora felicidad. Y según De Lubac este modo de comprender la historia de la salvación es absolutamente nueva, pues antes de Joaquín de Fiore nadie pensó así." «La primera edad trajo ortigas, rosas la segunda; la tercera aportaría lilas. Aparecerá un nuevo jefe, un papa universal de la nueva Jerusalén que vendría a renovar la religión cristiana» ${ }^{2}$ La teoría de Joaquín de Fiore en lo que respecta

De Lubac, 1989, La posteridad espiritual de Joaquín de Fiore, Madrid, Encuentro Ediciones, pp- 22-41

Huizinga, Johan, 1960, «El problema del Renacimiento", Hombres e ideas. Ensayo de historia de la cultura, Compañía general fabril editora, S. A. Buenos Aires, p- 243 
a la edad del Espíritu es interpretada de diferentes maneras, y sigue siendo fuente de reflexiones. Lo claro es que esa edad es de felicidad, de lo perfecto y verdadero

\section{Milenarismo y mesianismo peruano}

Milenarismo y mesianismo pregonan el fin de una era mediante cataclismos cósmicos y sociales, el retorno de los dioses y el cumplimiento de las profecías. Estos conceptos no son privativos de la cultura europea y cristiana, corresponden también a las culturas de otros espacios y épocas. Sucede que ante catástrofes naturales o sociales de extraordinaria trascendencia que con su impacto cambian drásticamente la realidad, la humanidad en su desesperado afán por sobrevivir y salvarse opta por darle sentido a los acontecimientos. En el corazón de las catástrofes que amenazan a los pueblos con la desaparición nacen esas ideas de salvación que brotan en forma de mitos. Estos mitos al darle significado a las catástrofes evitan la aniquilación y garantizan la continuidad de la vida y con ella la de la historia.

En la antigua cultura peruana estuvieron presentes estas ideas con el nombre de Pachacuti o cambio del mundo, así como de Inkarrí o la idea del retorno del Inca para reconstruir el mundo que los desastres históricos pusieron al revés. El concepto de Pachacuti que Felipe Huamán Poma de Ayala usó en su obra Nueva crónica y buen gobierno, integra «en un solo tejido, narraciones de las tradiciones orales andinas y las interpretaciones cristianas de acontecimientos bíblicos» ${ }^{3}$ Según como él interpreta el Pachacuti, categoría presente en la cosmología andina, este es el «concepto de la destrucción cósmica y cíclica del universo y su renovación» ${ }^{4}$ Según el estudio de Juan Ossio el cambio que se producía cada 500 años era el Pachacuti, y el cambio cada mil años era el Capac Huatan (Gran Año). Antes de los españoles hubo nueve pachacutis, que representan 4,500 años. La conquista puso fin a un quinto Capac Huatan.

La conquista y la colonización procesos que desestructuraron el Tahuantinsuyo constituyen un Pachacuti, es decir un apocalipsis en los Andes que puso al mundo incaico al revés con el inca dominado y convertido en siervo igual que su pueblo, en tanto que los españoles y su rey erigidos en amo y señor ocuparon la parte superior donde antes estuvo el Inca. Darle sentido y significado a esta catástrofe para que el mundo y su gente pudieran seguir viviendo generó el milenarismo andino que con la evangelización se tiño de mesianismo. Era pues imperativo crear la idea de un futuro posible donde todo podría ser restaurado en el corazón de esa vorágine apocalíptica.

Este mismo concepto de destrucción, desaparición, muerte y retorno encierra el mito de Inkarri. La cabeza del inca muerto por el conquistador, robada por algún andino y enterrada en un lugar desconocido de los Andes, estaría generando su cuerpo. Cuando estaría completo, el inca retornará, vencerá y expulsará a los invasores y el mundo inca quedaría restaurado.

En el siglo XVI, entre 1565 y 1571 ocurrió la prédica del Taki Onqoy en la vasta región de la sierra central con la zona de Ayacucho como centro. El Taki Onqoy o el baile de la desesperación como le han llamado algunos historiadores y antropólogos, fue según Sara

Adorno, Rolena,1992, Fondo Editorial de la PUCP, Lima, p. 219

$4 \quad$ Ob. cit. pp. 218 
Castro Klarén: una de las muchas respuestas al colapso del imperio inca. Según su prédica los dioses andinos o huacas que reinaron antes del dominio inca a los que los colonizadores creían muertos, retornarían, pelearían contra el Dios cristiano, lo derrotarían y a los españoles vencidos los arrojarían al mar, sus ciudades quedarían anegadas y de ellos no quedaría memoria. No retornarían los dioses incas, porque estos fueron los dominadores antes que los blancos de allende los mares. Todo esto sucedería porque el mundo se invertiría, daría una vuelta, es decir se produciría un Pachacuti o Pachatricray. Las huacas antiguas de antes del tiempo de los incas al retornar encontrarían su repositorio en el cuerpo de los hombres que se convertirían en templos vivientes que con la danza que llegaría hasta el éxtasis se tornarían en vectores de la furia contra las fuerzas opresoras. Toda opresión desaparecería incluyendo la dominación de los incas y de sus dioses: Pachacamac, el sol, la luna. El mundo volvería a ser como antes. ${ }^{5}$

Nuestro país según las especulaciones de los profesionales en ciencias sociales: antropólogos e historiadores, tiene espíritu y mentalidad milenarista y mesiánica. Los viejos traumas de la conquista así como de las dictaduras y caudillismos que desencadenaron frustración a lo largo de nuestra historia han sido sus causantes. Las viejas y nuevas utopías encuentran en los peruanos -como las huacas ancestrales de los años del Taki Onqoy- sus repositorios para desde allí proyectar sus sueños de un futuro donde es viable construir un país nuevo y feliz. Para esta construcción el pueblo peruano aguarda a su Mesías. Esta espera no es reciente, es antigua y a través del tiempo se renueva, como en el pensamiento del maestro Luis E. Valcárcel acuñado en Tempestad en los Andes. Según él, el aún irredento mundo andino de la segunda mitad del siglo XX estaba esperando a su Lenin. Desde ese tiempo hasta hoy han pasado muchos años; sin embargo el pueblo peruano en los momentos cruciales del acontecer social, político o de cualquier naturaleza de dimensión catastrófica que afecta la vida, piensa en el Mesías que está a punto de llegar para su salvación. De esta idea-esperanza tampoco están alejados la literatura y el arte. Pues, tenemos novelistas, poetas, músicos cuya producción apunta a ese ideal.

\section{Dos discursos mesiánicos}

En la historia inmediata de nuestro país hay dos momentos en los que emergió el fervor mesiánico emitiendo mensajes de un futuro nuevo y feliz. El primero acaeció en 1990 tras el fracaso de enormes dimensiones del primer gobierno de Alan García, durante la campaña eleccionaria para elegir al nuevo presidente y congresistas. El segundo despuntó en el año 2001, igualmente en otra campaña de la misma naturaleza, en repudio a la siniestra dictadura de Alberto Fujimori y de su asesor, el otro personaje tenebroso Vladimiro Montesinos.

En 1990, en algún lugar, región o zona cubiertos por una población de letrados sin partido, de trabajadores sin bandera, de gentes desencantadas por el fracaso de las promesas, o en el espacio rural ya liberado de la ataduras de la servidumbre impuesta por el gamonal o terrateniente gracias a la reforma agraria realizada por el gobierno de Velasco Alvarado, pero que seguía en la pobreza y en el olvido por la incuria, la vanidad

5 Castro-Klarén. 1990, «Discurso y transformación de los dioses en los Andes: del Taki Onqoy a «Rasu Niti»,El retorno de las huacas, 1990, Sociedad Peruana de Psicoanálisis, Lima. 
e indiferencia de los gobiernos que jamás pensaban en los cambios, o en los sectores populares de las zonas periféricas de las ciudades, brotó la frase: El chinito de la esquina va a derrotar al doctor Vargas Llosa. De igual modo en el año 2001 en el fragor de la batalla contra la dictadura fujimorista para restaurar la democracia y la paz brotó de la boca de una dama extranjera, otra frase: Mi cholo es sano y sagrado. Los dos enunciados son la punta de un gigantesco iceberg. Ambos discursos ocultaban (siguen ocultando) otros vastos discursos que contienen la historia de la pobreza, de la frustración, del olvido, de las desigualdades vividas compulsivamente con apariencia de eternidad, por las mayorías del pueblo peruano.

Veamos por partes. El enunciado de: El chinito de la esquina va a derrotar al doctor Vargas Llosa que fue usado a grandes voces durante la campaña eleccionaria en la que competían el ingeniero Alberto Fujimori y el escritor Mario Vargas Llosa, en su malla discursiva contiene al Perú troceado en dos mitades: el mundo de los pobres y olvidados, y el de los ricos y poderosos. En la primera parte del enunciado el término "chinito" al zambullirse en el túnel del tiempo, en una primera instancia trae de regreso al país entre 1849 y 1875, tiempo en que llegaron al Perú nutridos grupos de migrantes chinos traídos por los enganchadores para el trabajo en los algodonales y cañaverales de las haciendas de los ricos terratenientes de la costa. Vinieron para reemplazar al esclavo negro cuya libertad había sido proclamada por el presidente Ramón Castilla. Los chinos arribaron al Perú bajo la condición de "contratados», sistema muy favorable para el hacendado costeño porque abonaba su precio por el servicio de ocho años, al término de los cuales debido al extenuante trabajo, el chino quedaba reducido a un despojo humano y al finalizar su contrato quedaba librado a su suerte. El sistema del enganche era inhumano; a los enganchados se les prometía que al final del contrato podrían quedarse como hombres libres en el Perú o retornar a su lugar de origen. Pero, al llegar no encontraron el paraíso prometido sino explotación y miseria. Fueron traídos -según Pablo Macera- para envilecer los jornales en contra de los braceros indígenas. Con el tiempo los abusos y maltratos los llevaron a sublevarse aunque para ser reprimidos con brutal fiereza. Esos chinitos, durante la invasión chilena azuzados por los enemigos, se convirtieron en sus colaboradores y, en venganza cometieron mil fechorías, por ejemplo la destrucción del más importante ingenio azucarero a nivel sudamericano recién instalado en Chimbote y que asimismo en 1884, y pasada la guerra, recorrieron el Callejón de Huaylas sembrando terror bajo el comando de oficiales peruanos resentidos. En una segunda instancia el discurso también trae de regreso el tiempo en que muchos chinitos liberados se convirtieron en los tenderos de la esquina o los dueños de fondas de mala muerte en Lima. Ese "chinito" macilento, sucio, vicioso y pobre que vendía verduras y todo lo concerniente a las necesidades de la cocina de gente y familias de toda clase, desde las encumbradas de las zonas residenciales hasta de los barrios modestos, que en el enunciado no tienen representación, en la realidad encontró su representante en el candidato Alberto Fujimori. Además, la palabra "chinito" dejó de tener el significado racial para adquirir un contenido social que apuntaba a los sectores deprimidos y en extrema pobreza. En otras palabras, el "chinito", se convirtió en el candidato de los pobres del Perú de las tres regiones. Pero aún más, en el área rural tanto de costa, sierra y selva, el "chinito" llegó a ser para los campesinos e indígenas un individuo salido del seno de sus 
comunidades, para esto le sirvió mucho su imagen física y su deficiente uso del castellano. Definitivamente el candidato a la presidencia en aquella campaña eleccionaria era uno de ellos, un nativo, un individuo marginal sin sitio en el tejido social peruano al que el Perú oficial le había negado la vida durante 500 años. Este "chinito", que allí, en la vastedad de las Ilanuras arenosas de la costa y en el dilatado espacio de los Andes les hablaba durante sus apariciones del cambio de la realidad a las masas populares de las ciudades y a los que labran la tierra sin poder superar la pobreza, era el líder esperado que al asumir la presidencia los sacaría del atraso, de la miseria, del analfabetismo, del olvido. El "chinito" era el Mesías que conduciría a esa masa a la felicidad de un futuro que estaba a punto de llegar. Él les libraría de la pobreza. El milenio del olvido quedaría atrás cuando sería ungido como el mandatario de la nación. Había llegado el tiempo del Pachacuti, del Pachaticray, del cumplimiento de las profecías.

La segunda parte del enunciado referente a que el "chinito" vencería al doctor Vargas Llosa apunta al Perú oficial, de la minoría oligárquica, vanidosa y discriminadora que durante 500 años le negó la vida al país real. Ese Perú centralista, con un núcleo de poder llamado Lima, ciudad que desde 1821 tenía la idea de ser el país entero y que más allá de sus fronteras no existía sino la barbarie y que por tanto era un territorio para ejercer un colonialismo interior. Lima, un mundo indefinido, inclusive físicamente, de clima blando, donde jamás llueve, cosa que admira al mundo que se pregunta por qué Lima puede ser limpia si sobre ella nunca caen lluvias. Una ciudad con una sociedad que a Humboldt durante su visita le hizo pensar en cuál sería el porvenir de los niños porque sus padres y familiares no les dejaban enfrentarse al trabajo y los mantenían ociosos y servidos. Una sociedad que al hacer fotografiar a sus niños en los tiempos del daguerrotipo, para que posaran les ponían en la mano derecha un chicote, ${ }^{6}$ revelando con esta costumbre que los estaban preparando para manejar con ferocidad a su servidumbre casera, a sus esclavos, indios, negros o chinos que trabajaban en sus haciendas en condiciones inhumanas, en la creencia de que el mundo no cambiaría jamás y que el poder siempre estaría en sus manos. Una Lima que a Flora Tristán le inspiró lástima porque allí señoreaba la ignorancia, sus señoronas en su mayoría semianalfabetas; sus militares, cobardes; el presidente del país, inútil; y sus congresistas eran nada más que oradores rimbombantes cuya ambición era apropiarse de los fondos fiscales. La Lima del niño Goyito, amante del toreo y de las fiestas, de los ricos que al haberse enriquecido con el negocio del guano ya no querían beber vino nacional sino francés, ni usar ropa y muebles confeccionados en Lima, sino los traídos de París de la belle époque. La Lima de fines de la segunda mitad del siglo XX que a través de la radio y televisión hace gala de ser jaranera (como si esto fuera un virtuosismo en búsqueda del desarrollo) con falsos doctores, todos señoritos, blancos, vanidosos, a quienes según José María Arguedas los migrantes andinos le enviaron una carta dándoles la noticia de que habían llegado y estaban en los arenales, con su corazón, sus ríos, sus danzas y canciones, aguardando con paciencia la hora en que el mundo se reordenaría al darse la vuelta.

Ugarte Eléspuru, Juan, 1967 Lima y lo limeño, Editorial universitaria. Lámina IX: «Un niño limeño». El autor en su largo comentario dice: «Ninguna imagen puede representar mejor a una cierta porción de nuestra idiosincrasia limeña, dulzona, malcriada e imbuida de prejuicios heredados que esta de la litografía sin firma ( ) que nos muestra a un «niño» () luciendo su atuendo virreinalicio y empuñando con altiva puerilidad como juguete un latiguillo» 
Este fue el contenido del enunciado: El chinito de la esquina va a derrotar al doctor Vargas Llosa. Había llegado el Mesías, el salvador, que derrotaría en las urnas al representante del sector poderoso. El tiempo del Pachacuti se había hecho presente y el mundo daría la vuelta. En las urnas ganó el "Chinito" Luego vinieron las consecuencias... ¿Fue verdad que el Pachacuti había llegado? ¿Fujimori era el héroe salvador? ¿0 el falso Mesías, el impostor? La historia peruana durante su gobierno está llena de hechos contradictorios. Primero vino el shock, luego la centralización más aguda a la del pasado, es decir volvió el colonialismo interno; de seguido se desplegó una cadena interminable de privatizaciones: todas las empresas y fábricas nacionales fueron vendidas, el país fue desindustrializado, además de quedar desmantelado. Vinieron luego el golpe de estado, la dictadura, la violencia e intolerancia, la desaparición del producto de las ventas, la violación de los derechos humanos. Llegó la desideologización, el repliegue de los partidos políticos y con ello el colapso de la frágil democracia, emergió la corrupción, la figura apocalíptica de Montesinos, y mucho más. Asomó el etnocidio, no otra cosa pudo significar la esterilización forzada de las mujeres pobres, todas indígenas. El mundo campesino de todo el país que votó por el falso Mesías con la creencia de que había llegado el Pachacuti, había votado por su desaparición.

El segundo discurso: Mi cholo es sano y sagrado, que brotó en el corazón hirviente de la lucha contra la dictadura, igual que el primero oculta también no solo uno, sino muchos discursos. Ese "cholo" era Alejandro Toledo, candidato presidencial, a quien luego de su victoria el Papa Juan Pablo II al igual que los peruanos llamó el primer presidente indio. Peruano de ancestros provincianos y andinos, era un auténtico hijo de la nación, no como el "chinito" de sangre japonesa, con partida de nacimiento fraguada astutamente en el momento de la migración, para hacerlo aparecer como nacido en el Perú e inclusive un 28 de julio, fecha del aniversario nacional.

El "cholo" que con la Marcha de los cuatro suyos derribó la dictadura del falso Pachacuti, encarnaba al Perú profundo, el mundo popular marginado y desclasado, con campesinos e indígenas que estaban a la espera de un mundo mejor. Este universo fue nuevamente deslumbrado por un nuevo Mesías, no impostor sino real por ser andino y racialmente indígena. Era casi un Inkarrí. Si no era el real y auténtico, era por lo menos su representante, su mensajero o embajador. Inauguró su gobierno en Machu Picchu ejecutando el ritual del pago a la tierra.

Este "cholo" era "sano", no estaba contaminado con los vicios de los que por centurias detentaron el poder, por 500 años exactamente. Venía investido de poderes para purificar el país que había sido manchado por el gobierno vicioso del falso Mesías. Era "sagrado", porque era la encarnación de las huacas que retornaban, como en los tiempos del Taki Onqoy, para vencer y derrotar al enemigo. En efecto lo derrotó; y sobre los escombros de su derrota restauraría el orden perdido, vencería a la corrupción, al crimen, a la violencia, al latrocinio, a la mentira. El país sería purgado, purificado, resucitaría. El Mesías exorcizaría del país a las fuerzas del mal.

Pero desafortunadamente este cholo sano y sagrado no era libre, tenía dueño; pues el enunciado al decir de entrada: «Mi cholo» connota que él pertenecía a alguien. ¿A quién pertenecía el "cholo sano y sagrado"? No a un propietario real e individual, sino a un sistema; 
pues primero, toda su infancia no había transcurrido en la provincia serrana de Ancash, sino en Chimbote, lugar multicultural, que debido al auge de la industria de la harina de pescado era un hervidero de razas, culturas, lenguas, vicios, astucias; en contacto con religiosos y turistas norteamericanos, alejado de la cultura andina y de los problemas de las mayorías indígenas; $y$, después su formación profesional se realizó en una universidad estadounidense, que es como decir en el corazón del imperio. Allí fue instruido, educado, entrenado para gobernar a un país periférico que vale decir una semicolonia de la potencia del norte. No fue la encarnación del auténtico Pachacuti, concepto andino cuyo contenido y significado desconoce. No habla quechua y por tanto no posee la sensibilidad andina ni conoce la cultura ancestral que esa lengua contiene. En su provincia, Cabana y toda la zona norte del departamento de Ancash, el quechua ha pasado al olvido; desde antes del s. XX la gente habla castellano y no practica los rituales del Perú remoto, si los conoce es a través de la folclorización que realizan las fiestas religiosas cristianas. No conoce la cosmología andina ni a los dioses antiguos de los Andes y por tanto tampoco sabe de los rituales ancestrales igual que el pequeño sector de los peruanos que los conoce como resultado de la lectura de los libros escritos por algunos etnólogos, antropólogos o historiadores. Desconoce la vida en los Andes, las penurias, las aspiraciones, las alegrías y desencantos. Por último cayó en los mismos vicios que caracterizaron a los gobernantes de todos los tiempos.

Al revés del discurso de: El chinito de la esquina derrotará al doctor Vargas Llosa cuyo emisor es anónimo, el enunciado: Mi cholo es sano y sagrado, si tuvo un emisor real. La persona que jugó ese papel fue una europea residente en los Estados Unidos de Norteamérica, donde ejercía la docencia en una universidad; $y$, además era esposa (Elian Karp) del candidato. Al emitir el mensaje tenía la creencia de que los receptores (los peruanos) seguían pensando como en los tiempos del inca. Lo que no sabía era que esos receptores en su mayoría viven alejados del pensamiento andino y pocos están enterados, y estos son los pocos letrados que han leído libros escritos por algunos académicos dedicados a la investigación etnohistórica. Ella sí sabía de ese pensamiento, del Pachacuti y de las huacas, por ser antropóloga y por tanto pensaba que su mensaje al calar en el espíritu de los receptores estos lo llevarían mediante su voto al cholo sano y sagrado al sillón presidencial, porque habían llegado el Pachacutiy el héroe salvador. Esto por una parte, pero por otro lado si ella sabía que los peruanos culturalmente no estaban enterados del viejo pensamiento andino, con su mensaje estaba actuando como un colonizador, porque nos consideraba como individuos habitantes de un mundo culturalmente estancado en un pasado lejano al que no queremos abandonar y por tanto impresionables con una declaración y una promesa de un futuro nuevo y feliz. Entonces, el cholo sano y sagrado venía no solo a exorcizar del Perú la obscenidad instaurada por Fujimori, sino también portando la civilización con su modernidad, su globalización, etc., cada una con su parafernalia respectiva.

¿Cuál es la conclusión o qué lección se extrae de este proceso? ¿El Perú ha superado la mentira, el engaño, la corrupción, la frustración, los viejos traumas? ¿Somos un país con el defecto que linda con el masoquismo que actualiza sus traumas impuestas por catástrofes pasadas a las que suma el impacto de nuevas frustraciones? Hay verdades que no se pueden negar. El mesianismo y milenarismo son solo modos de darle sentido a las catástrofes naturales, sociales o políticas, para sembrar en el espíritu y la conciencia 
colectiva caída en desgracia alta capacidad de resistencia para garantizar la continuidad de la vida y de la historia. Como ideologías capaces de ser llevadas a la práctica son inviables. Convencimiento que nos lleva a pensar que las huacas han sido víctimas de la muerte real. Todas están muertas, incluyendo el apu limeño, hoy llamado San Cristóbal que hace 500 años fue exorcizado, porque según los españoles los apus y las huacas eran los habitáculos de los demonios. No volverán jamás. Nuestro mundo está lleno de los huesos de los dioses muertos. Rolena Adorno escribe: «La conclusión que Guamán Poma saca de estar el mundo al revés es decir, la "señal que no hay Dios". (...) La negación es un concepto que no se puede materializar en el campo pictórico» Por eso no hay un ícono en su Nueva crónica y buen gobierno, sobre este tema. ' Los peruanos debemos superar nuestras frustraciones y los traumas del pasado. No hacerlo es un modo de permanente autovictimización. Debemos cultivar la conciencia que en el eslabonamiento cronológico de la historia el pasado está al servicio de la vida. Pero para esto es necesario no convertir el presente en epígono del pasado, porque esto sería abogar por la congelación. Se dice que solo el presente tiene la fuerza para interpretar el pasado. Si esto es así, el pasado no es un programa, un proyecto, como lo dijo en su momento José Carlos Mariátegui.

\section{Misión israelita del Nuevo Pacto Univesal}

En este tiempo de comienzos del siglo XXI dos son los fenómenos importantes en el mundo: la globalización y la mundialización. El primero es una categoría aplicable a los ámbitos de la economía y la tecnología, en tanto que la segunda al espacio de la cultura. ${ }^{8}$ En todas partes funciona el dólar, el ordenador, el celular, desencadenando una uniformización. No sucede igual con la mundialización; aquí se produce la heterogeneidad cultural, una heterogeneidad no pasiva sino conflictiva debido a que las culturas nativas reaccionan ante el ingreso de culturas diferentes con una conducta defensiva. La mundialización no es un proceso homogeneizador sino precipita la diversidad cultural y una coexistencia. Después de la guerra fría que produjo el desplome del equilibrio mundial del poder bipolar, las culturas de los países periféricos adoptaron dos movimientos, por el primero enfatizó su conducta defensiva, por el segundo sacó a flote su arsenal cultural ancestral, incluyendo el rescate de sus manifestaciones más antiguas, fenómeno que siguiendo a Pablo Macera llamaríamos la rearcaización.

Analistas europeos y norteamericanos llaman a este acontecimiento el «Fenómeno de indigenización», es decir el retorno a las raíces en busca de la identidad como forma de resistencia a la agresión occidental, que abarca no solo a América Latina sino al mundo entero, entre ellos al mundo del Islam. En el Perú, al comienzo se le llamó rebrote del indigenismo que por ejemplo en literatura ha originado la literatura andina ${ }^{9}$ alentada por docentes universitarios de procedencia campesina y algunos críticos que asumieron la misma línea cultural. Este fenómeno ha venido acompañado del ascenso de los sectores

\footnotetext{
Adorno, R. Ob. cit. p 216

8 García-Bedoya, Carlos, 2012, Indagaciones heterogéneas. Estudios sobre literatura y cultura. Grupo Pakarina SAC. Lima., pp.31-47

9 En el seno de esta literatura muchas novelas asumen una posición milenarista y mesiánica, por ejemplo Rosa cuchillo de Óscar Colchado Lucio., a diferencia de otras que proponen un mestizaje universal armónico, como es el caso de la novela País de Jauja de Rivera Martínez.
} 
campesinos deprimidos de costa y sierra como consecuencia de la reforma agraria de 1970 y del «desborde popular», procesos que iniciaron un cambio en el Perú situándonos en los inicios de la modernización. Las masas deprimidas de las ciudades y del campo han accedido a la urbe, a la economía informal que en muchos casos son el germen de capitalistas y el acceso a la educación; hoy el colegio y la universidad están llenos de estudiantes y profesores de extracción popular y rural. En este ámbito los políticos salen ganando en las elecciones no por ser occidentalistas, sino porque adoptan conductas que se acercan a lo étnico y su cultura, fenómeno que también ocurre en el campo de los profesionales en ciencias sociales y en los escritores que ganan prestigio con sus novelas o poemas con los que asumen un etnocentrismo que a veces linda con el fundamentalismo.

En el ámbito religioso, el renacimiento religioso se ha mostrado más mestizo, más híbrido que en el s. XVII como un gesto de vuelta a la identidad. Hoy, por ejemplo, ya no es cosa del pasado el uso de rituales antiguos como la ofrenda a los apus o el brindis de la chicha a Pachamana que hasta los turistas extranjeros lo practican por curiosidad y diversión sin conocer su significado; la danza de tijeras en tiempos pasados netamente ritual, hoy ha sido convertido en espectáculo por el mismo pueblo andino. Se rescata y practica abiertamente un culto religioso híbrido, mitad popular, ancestral o cristiano.

En la segunda mitad del s. XX la modernización planetaria no trajo para todos el bienestar prometido. Su fracaso apoyó el resurgimiento de las religiones como respuesta a un mundo inseguro por los cambios permanentes que ponían en riesgo a las identidades. La religión se convirtió en refugio por la solidaridad, el apoyo mutuo que practican sus creyentes, valiosos y salvadores recursos sobre todo en el mundo de los migrantes. Nacieron entonces numerosos grupos de sectas cada una prometiendo mejores soluciones a la pobreza y la inseguridad en la vida a diferencia de los Estados que no movían un solo recurso para el amparo contra esos traumas de la modernización. En la realidad peruana ese fue el campo abonado para la aparición de un movimiento que se fortificó con los años desde 1956 hasta 1968, lapso en que se fundó la Misión Israelita del Nuevo Pacto Universal, por un excomunero y exseminarista adventista nacido en la comunidad de Huarhua, Arequipa, Ezequiel Ataucusi Gamonal Fue un movimiento eminentemente milenarista y mesiánico. Su característica: la mezcla de elementos bíblicos y andinos. Pregonaba la llegada del Mesías encarnado en su líder que quiso llegar a la presidencia del país y candidateó hasta por dos veces., la última vez paralelamente con Fujimori, aunque después renunció. El FREDEMO de Vargas Llosa tentó su apoyo, pues sus doscientos mil adeptos constituían un codiciable caudal de votos. Su símbolo, un pescadito, que según relato del propio Ezequiel Ataucusi le salvó de la muerte en un río, símbolo que evoca los dos pescados cruzados de los cristianos del tiempo de las catacumbas. El brazo político del movimiento fue el Frente Popular Agrícola del Perú. Ataucusi conocía profundamente la Biblia y recordaba aunque de forma laberíntica sus pasajes que le servían de sustento a su ideología. Sea como fuere, este movimiento es un cristalino ejemplo del mesianismo peruano de carácter popular y rural. Su líder carismático quizás no accedió a una educación formal, ni conoció la universidad. ¿Acaso después de la Biblia leyó tratados políticos socialistas y todo cuanto necesitó para llevar a cabo su aventura? Su origen humilde, su vida llena de penurias y traumas, su inquietud lo emparentan con otros personajes históricos, con don Felipe Huamán Poma 
de Ayala y otro modesto soñador lejano en el tiempo y en el espacio, por ser italiano, el molinero Menocchio. Huamán Poma de Ayala, Ezequiel Ataucusi y Menocchio, sin duda se aprovisionaron intelectualmente de la cultura popular sobre la que ha escrito Mijail Bajtin. Carlo Ginzburg al estudiar al molinero italiano que formuló una particular idea del origen de Dios, del universo y de los hombres, en una parte de su extenso tratado asegura que los elementos populares en Menocchio están engarzados en ideas claras que engloban desde el radicalismo religioso y un naturalismo de tendencia científica hasta aspiraciones utópicas de renovación social. En sus ideas hoy recogidas por Ginzburg en su libro El queso y los gusanos. El cosmos, según un molinero del siglo XVI está vigente la convergencia de las ideas de los intelectuales de aquel tiempo con las del modesto y humilde molinero que alimentó su espíritu con la lectura de diversos libros en un orden que no fue orden.

El movimiento de Ezequiel Ataucusi ha sido estudiado durante 30 años, por el prestigioso antropólogo peruano Juan Ossio en su libro: El Tahuantinsuyo bíblico: Ezequiel Ataucusi Gamonal y el mesianismo de los israelitas del nuevo pacto universal ${ }^{10}$ Asevera allí que ese movimiento contuvo a Sendero Luminoso por representar una alternativa en la búsqueda del cambio de la realidad, y propició indirectamente a su derrota. Afirmación que se complementa con la del economista Hernando de Soto que manifiesta que fueron los campesinos que iniciaron por su cuenta salir de la pobreza pasando de clase baja a migrantes y luego a informales, y de informales a la nueva clase media, quienes vencieron a ese movimiento que usó el terror. De Soto asevera también que la nueva clase media peruana nació en Ayacucho.

\section{A modo de conclusión}

De lo hasta aquí expuesto salta a la vista una conclusión contundente. La ausencia de una verdadera conciencia política en la ciudadanía peruana de los sectores sociales deprimidos. Este espacio social que viene arrastrando una desbordante marginalidad desde 1821 aguarda la solución de sus problemas. En este trance es presa fácil de quienes han hecho de la política una herramienta de negocio.

Ossio, J. 2014, El Tahuantinsuyo bíblico. Ezequiel Ataucusi Gamonal y el mesianismo de los israelitas del nuevo pacto universal. Biblioteca Nacional del Perú, 400 pp. 


\section{REFERENCIAS BIBLIOGRÁFICAS}

Adorno, R. (1992). Cronista y príncipe. La obra de don Felipe Guamán Poma de Ayala, Lima: PUCP

Castro, K. (1990). «Discurso y transformación de los dioses en los Andes: del Taki Onqoy a "Rasu Ñiti", El retorno de las huacas, Lima: Sociedad Peruana de Psicoanálisis. (407-423).

De Lubac, H. (1989). La posteridad espiritual de Joaquín de Fiore. Madrid: Encuentro Ediciones Eliade, M. (1972). El mito del eterno retorno, Madrid: Alianza/Emecé.

Huizinga, J. (1960). «El problema del Renacimiento» Hombres e ideas. Ensayos de Historia de la Cultura. Buenos Aires: Compañía General Fabril editora, S.A. (215-254).

Huntington, S. P. (1997). El choque de civilizaciones y la reconfiguración del orden mundial. Barcelona: Paidós Ibérica, S.A.

Millones, Luis (Comp.) (1990). El retorno de las huacas. Lima: Sociedad Peruana de Psicoanálisis Morales Mena, J. (2010). «Marcos Yauri Montero: La crítica literaria que escribe la voz», Telúrica y magnética. Revista de Escritura Creativa de la Unidad de Posgrado de la Facultad de Letras y Ciencias Humanas de la Universidad Nacional Mayor de San Marcos, 3. (230236).

Ossio, J. (2014). El Tahuantinsuyo bíblico. Ezequiel Ataucusi y el mesianismo de los israelitas del nuevo pacto universal. Lima: Biblioteca Nacional del Perú. 